\title{
Degradation of nucleic acid derivatives by rumen bacteria in vitro
}

\author{
By A. B. MCALLAN and R. H. SMITH \\ National Institute for Research in Dairying, Shinfield, Reading $R G 29 A T$ \\ (Received 7 September $1972-$ Accepted 30 October 1972) \\ I. Purine or pyrimidine bases, nucleosides or nucleotides were incubated, in vitro, with \\ whole rumen contents, or with a cell-free filtrate prepared from rumen contents of calves \\ fed on diets of flaked maize and hay. \\ 2. During incubations with whole rumen contents, all derivatives bearing a side amino \\ group were deaminated to varying extents. \\ 3. All nucleotides and nucleosides were rapidly degraded to the parent base or its desamino \\ counterpart. \\ 4. Evidence suggests that guanosine was degraded to guanine before deamination occurred \\ whereas deamination preceded ribosidic cleavage for adenosine. \\ 5. Xanthine, uracil, hypoxanthine and thymine resisted further degradation to varying \\ degrees. \\ 6. Little or no breakdown was observed when any derivative was incubated, in vitro, with \\ cell-free preparations.
}

Although the utilization of preformed purine and pyrimidine bases, and nucleosides (Lichtenstein, Barner \& Cohen, 1960; Beck, Ingraham, Neuhard \& Thomassen, 1972), and the catabolic breakdown of derivatives (Hayaishi \& Kornberg, 1952) have been studied for some non-rumen bacteria, little is known about the action of rumen micro-organisms on nucleic acid derivatives. McAllan \& Smith ( 1973 ) found that when samples of RNA or DNA were introduced into the rumens of calves they were rapidly broken down and the nucleotides, nucleosides, and purine and pyrimidine bases formed disappeared much more rapidly than could be accounted for by transfer to the lower digestive tract. Similar, though somewhat slower, breakdown was observed when RNA or DNA were incubated, in vitro, with calf whole rumen contents, but there was a steady accumulation of certain bases over the period of incubation (McAllan \& Smith, 1973). In an attempt to clarify the pathways involved in these metabolic changes and the reasons for differences in rates of disappearance of endproducts in in vivo and in vitro experiments, the degradations of nucleic acid derivatives during in vitro incubations with rumen contents have been studied.

\section{METHODS}

Animals and feeding. Castrated male Friesian calves, aged I 5-39 weeks, equipped with rumen cannulas were used throughout this work. All animals were maintained on a diet of equal proportions of flaked maize and hay with suitable mineral and vitamin supplements.

Collection and treatment of samples. The collection and treatment of rumen samples, and the preparation of cell-free filtrates were as described by McAllan \& Smith (1973). 


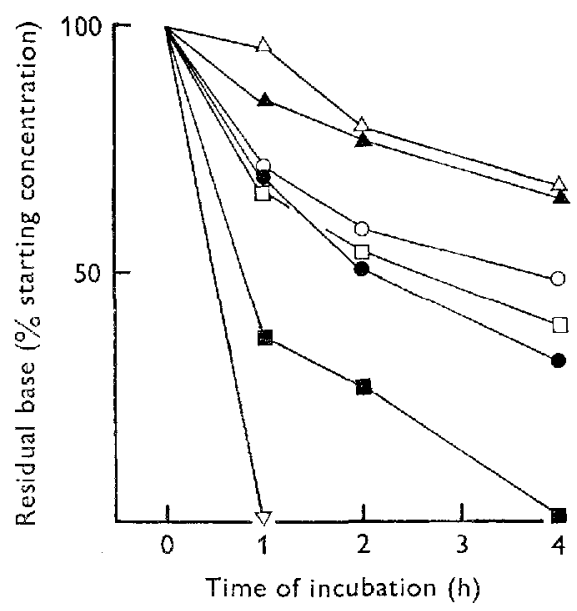

Fig. I. Survival of purine and pyrimidine bases with time during in vitro incubation with calf whole rumen contents as described on p. 468 . Results are expressed as a percentage of the initial concentrations. The bases examined, and their initial concentrations $(\mu \mathrm{mol} / \mathrm{ml})$ were: xanthine (I.05), $\Delta$; uracil (I·43), $\Delta$; hypoxanthine $(\mathrm{I} \cdot \mathrm{I} 8), O$; thymine $(\mathrm{I} \cdot 27)$, (I·19), $\square$; guanine ( $\mathrm{x} \cdot 06), \mathbf{b}$; cytosine $(\mathrm{I} \cdot 24), \nabla$.

Incubation procedure. Solutions of the materials under examination (I $\mathrm{ml}$ containing approximately $30 \mu \mathrm{mol}$ of derivative) were incubated, in vitro, with $24 \mathrm{~g}$ whole rumen contents or $24 \mathrm{~g}$ cell-free preparation according to the procedure of McAllan \& Smith (I973). The nucleotides and nucleosides were all soluble in water at the concentrations used but the bases were dissolved in a minimum volume of sodium hydroxide solution (Io $\mathrm{mmol} / \mathrm{l}$ ) and made up to the required volume with water. During the incubation procedure the $\mathrm{pH}$ of the mixtures remained virtually the same as that of freshly collected rumen contents, within the range $6 \cdot 8-7 \cdot \mathrm{r}$.

Identification of products. Ultrafiltrates were prepared from the incubation mixture according to the procedure of Gregory (1954) using cellophane tubing of $6 \mathrm{~mm}$ diameter (Union Carbide International Co., New York). Samples of ultrafiltrates ( $2 \mathrm{ml}$ ) were chromatographed on a $900 \mathrm{~mm} \times 15 \mathrm{~mm}$ column of Sephadex G-10 Dextran gel (Pharmacia (GB) Ltd, London). Chromatographic conditions and the identification of the eluted peaks, by position of elution and by thin-layer chromatography on cellulose, were as described by McAllan \& Smith (1973).

Chemicals. Inosine, xanthine, hypoxanthine and uridine mononucleotide $\left(2^{\prime}, 3^{\prime}\right.$ mixed isomers) were obtained from British Drug Houses, Poole, Dorset. Xanthosine was obtained from Phasesep R and D Chemical Co., Queensferry, Flintshire. The other bases, nucleosides and nucleotides used were obtained from Koch-Light Laboratories, Colnbrook, Bucks.

\section{RESULTS}

In the following sections, all values given for the amounts of derivatives removed or degraded during incubation and those surviving incubation are mean values ( \pm SEM) expressed as percentages of the initial concentrations, for three experiments. 


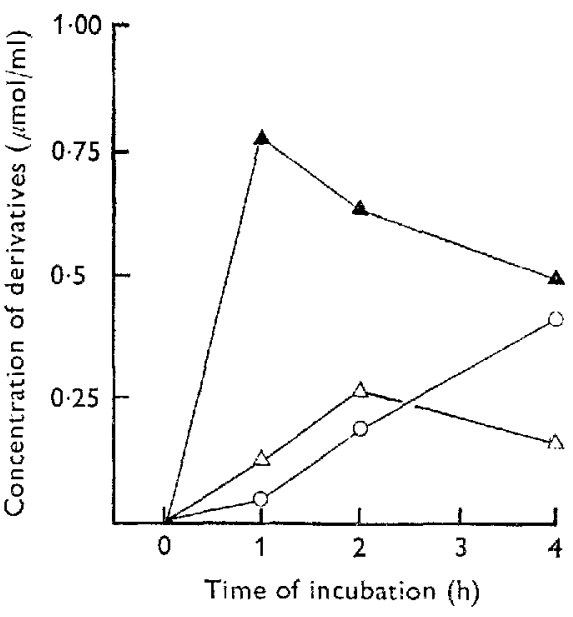

Fig. 2

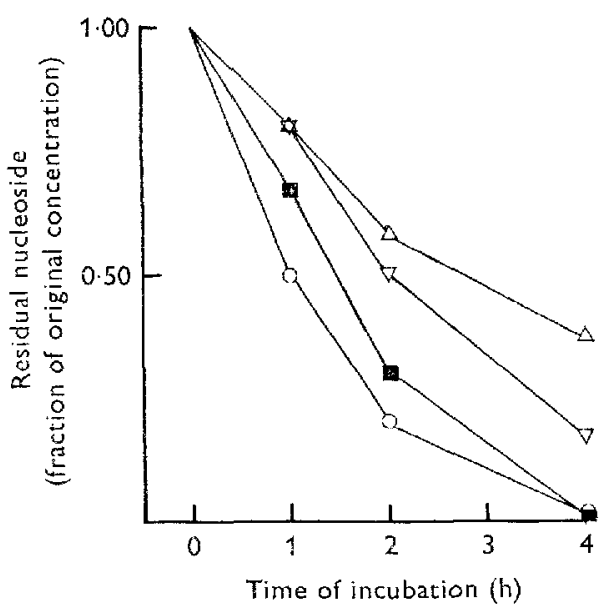

Fig. 3

Fig. 2. Increases, with time, in the concentrations of oxy bases produced from the corresponding amino bases during incubation in vitro with calf whole rumen contents as described on p. 468 . Results are expressed as $\mu \mathrm{mol} / \mathrm{ml}$ incubation mixture; the bases produced, starting material, and initial concentrations $(\mu \mathrm{mol} / \mathrm{ml})$ were: hypoxanthine from adenine ( $I \cdot 19), O$; xanthine from guanine (I-06), $\Delta$; uracil from cytosine $(\mathrm{I} \cdot 24), \boldsymbol{\Delta}$.

Fig. 3. Removal of purine and pyrimidine nucleosides, with time, during incubation in vitro with calf whole rumen contents as described on p. 468. Results are expressed as a percentage of the initial concentration. 'The nucleosides used with their initial concentrations $(\mu \mathrm{mol} / \mathrm{ml})$ were: xanthosine (I·I3), $\wedge$; guanosine (I·I3), inosine (I·I9), $O$; cytidine $(\mathrm{I} \cdot 32), \nabla$.

\section{Degradation of derivatives by whole rumen contents}

Purine and pyrimidine bases. Purine and pyrimidine bases (adenine, guanine, thymine, uracil, cytosine, hypoxanthine and xanthine) were individually incubated with calf whole rumen contents, for varying periods of time, at final concentrations of $\mathrm{I} \cdot \mathrm{O}-\mathrm{I} \cdot 4 \mu \mathrm{mol} / \mathrm{ml}$ incubation mixture as described on p. 468 . Fig. I shows the results of typical experiments showing the rates of removal of cach of the bases, with time, during the incubations. Uracil and xanthine were the most resistant to attack, and after $4 \mathrm{~h}$ incubation both were degraded to similar extents. The amounts of these bases (means $\perp \mathrm{SEM}$ ), expressed as a percentage of the initial concentration, that survived after $4 \mathrm{~h}$ incubation were $62 \pm 5$ and $63 \pm 5$ respectively.

Hypoxanthine, thymine and adenine were fairly resistant to breakdown, and corresponding values for amounts surviving after $4 \mathrm{~h}$ incubation were $45 \pm 4,30 \pm 2$ and $3^{8} \pm 2$ respectively. Guanine was broken down more rapidly, only $39 \pm 4$ survived after $\mathrm{I} h$ and it had completely disappeared after $4 \mathrm{~h}$. Cytosine was completely removed within $\mathbf{I}$ h. The above results show the disappearances of individual bases irrespective of their fates. Those bases with side amino groups were, to varying extents, degraded by aminohydrolase activities. Fig. 2 shows examples of the rates of production of the corresponding oxy bases obtained.

Cytosine, which rapidly disappeared (see Fig. I), was largely converted into uracil, and after only $I \mathrm{~h}$ incubation the mean percentage ( \pm SEM) as uracil was $63 \pm 4$. The production of hypoxanthine from adenine appeared to occur fairly uniformly 


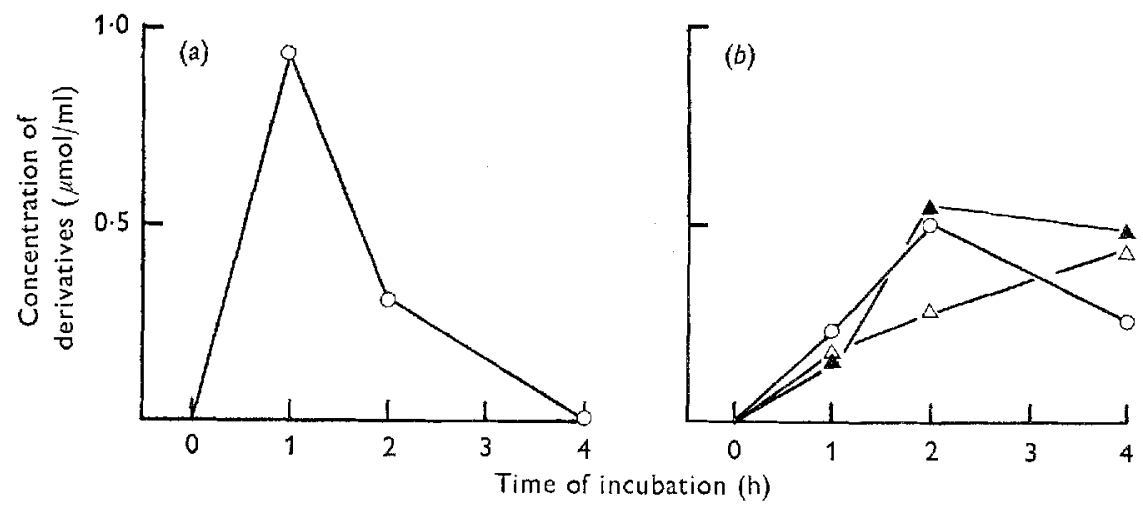

Fig. 4. Production of desamino derivatives, with time, during incubations of purine and pyrimidine amino nucleosides with calf whole rumen contents in vitro as described on p. 468 . Results are expressed as,$\mu \mathrm{mol} / \mathrm{ml}$ incubation mixture. (a) Inosine produced from adenosine (initial concentration $\mathrm{r} \cdot 20 \mu \mathrm{mol} / \mathrm{ml}$ ), $O$. (b) Oxy bases produced from amino nucleosides (with initial concentration $(\mu \mathrm{mol} / \mathrm{ml})$ in parentheses) were: hypoxanthine from adenosine $(\mathrm{r} \cdot 20), 0$; xanthine from guanosine $\left(I_{1} \cdot \mathbf{x}_{3}\right), \triangle$; uracil from cytidine $(\mathrm{I} \cdot 32), \mathbf{A}$.

over the incubation period (Fig. 2 ), and after 4 h hypoxanthine accounted for $33 \pm 2 \%$ of the adenine initially present. Some xanthine was also observed after $4 \mathrm{~h}$ incubation, accounting for $7 \pm 2 \%$ of the starting concentration of adenine. The maximum production of xanthine from guanine was observed after $2 \mathrm{~h}$ incubation, accounting for $22 \pm 4 \%$ of the initial concentration, and the xanthine produced was partly removed after $4 \mathrm{~h}$.

Nucleosides. The stabilities of the individual nucleosides adenosine, guanosine, thymidine, uridine, cytidine, inosine, and xanthosine during incubation with calf whole rumen contents were examined. Fig. 3 shows typical examples of the degradation, with time, of these nucleosides incubated in vitro. All were degraded to varying extents over the $4 \mathrm{~h}$ incubation period. Adenosine, uridine and thymidine were completely removed within $\mathrm{I} h$. Guanosine and inosine survived to the extent of $63 \pm 5$ and $47 \pm 5 \%$ respectively after $\mathrm{I} h$ incubation but were completely removed after $4 \mathrm{~h}$. Xanthosine and cytidine were the most resistant to breakdown, and after $4 \mathrm{~h}$ incubation, $37 \pm 5$ and $18 \pm 2 \%$ respectively survived.

Certain of the breakdown products formed during the incubations described above, are shown in Fig. 4. Adenosine was deaminated to inosine within I h (Fig. 4(a)) and the mean percentage $( \pm \mathrm{SEM})$ of the initial concentration recovered in this form was $78 \pm 5$. Inosine itself was completely removed after $4 \mathrm{~h}$ incubation (see Fig. 3 ) and $30 \pm 3 \%$ of the initial concentration was recovered as hypoxanthine (see Fig. 5). The inosine produced from adenosine was also subjected to nucleosidase action giving hypoxanthine (Fig. $4(b)$ ) which, after $4 \mathrm{~h}$ incubation, accounted for $26 \pm 2 \%$ of the initial concentration of the adenosine. For the other nucleosides with side amino groups the only degradation products detected were desamino bases, of which typical examples are shown in Fig. $4(b)$. No deaminated nucleosides were found. Xanthine increased progressively, in incubation mixtures containing guanosine, over the $4 \mathrm{~h}$ period and accounted for $36 \pm 5 \%$ of the initial concentration, whereas the uracil 


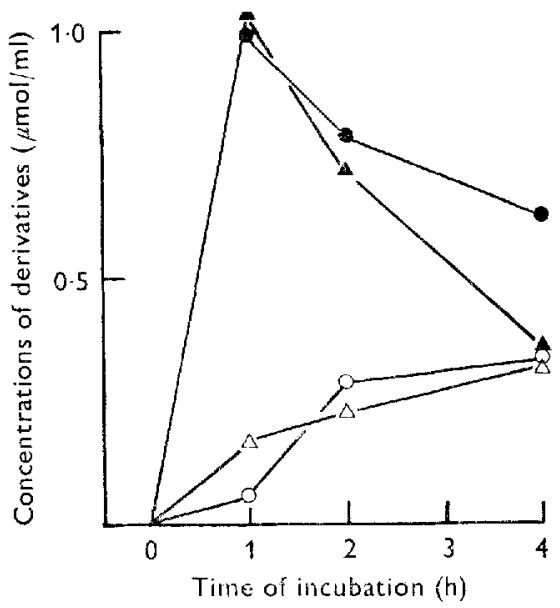

Fig. 5. Incteases, with time, in the concentrations of bases produced during incubation of the corresponding nucleosides with calf whole rumen contents in vitro, as described on p. 468 . Results are expressed as $\mu \mathrm{mol} / \mathrm{ml}$. The bases produced, the original nucleosides used, and their initial concentration $(\mu \mathrm{mol} / \mathrm{ml})$ were: xanthine from xanthosine ( $\left.1 \cdot{ }^{3}\right), \Delta$; hypoxanthine from inosine $(\mathbf{I} \cdot \mathrm{r} 9), \mathrm{O}$; uracil from uridine $(\mathrm{I} \cdot 3 \mathrm{I}), \mathbf{A}$; thymine from thymidine $(\mathrm{I} \cdot 32)$,

obtained from cytidine reached a maximum value after $2 \mathrm{~h}(42 \pm 6 \%)$ and had decreased again after $4 \mathrm{~h}$ (see Fig. $4(b))$.

Nucleosidase activity on the other nucleosides that were tested resulted in varying proportions of the corresponding bases being produced. Fig. 5 shows results for the amounts produced, with time of incubation, in typical experiments. Uridine and thymidine were rapidly degraded and mean recoveries ( \pm SEM) as the corresponding bases were $76 \pm 4$ and $73 \pm 6$ respectively after $\mathrm{I} h$. The production of xanthine and hypoxanthine from their nucleosides occurred steadily over the $4 \mathrm{~h}$ incubation period and the bases accounted for $30 \pm 4$ and $30 \pm 6 \%$ respectively of the initial nucleoside concentrations after $4 \mathrm{~h}$.

Nucleotides. Mixed 2', $3^{\prime}$, isomers of uridylic, guanylic, adenylic and cytidylic acids were incubated as described on p. 468 . After $4 \mathrm{~h}$ incubation (only $4 \mathrm{~h}$ incubates were examined) all the mononucleotides were completely removed except cytidylic acid, for which $9 \pm 3 \%$ survived. Adenylic and guanylic acids had apparently undergone breakdown similar to that of their nucleosides, presumably after dephosphorylation; $43 \pm 5$ and $40 \pm 2 \%$ of the initial concentrations of $\mathrm{I} \cdot 3 \mathrm{I} \mu \mathrm{mol} / \mathrm{ml}$ respectively were recovered as the corresponding oxy bases. Uracil was the only end-product from uridylic acid and the main end-product from cytidylic acid, accounting for $62 \pm 6$ and $62 \pm 5 \%$ respectively of both initial concentrations of $1 \cdot 48 \mu \mathrm{mol} / \mathrm{ml}$. No nucleosides were detected in any experiment.

\section{Degradation of derivatives by cell-free rumen fuid}

Derivatives were incubated with cell-free filtrate as described on p. 468 and were examined as described above for incubations with whole rumen contents. Little or no degradation was observed when thymine, uracil, cytosine, hypoxanthine or xanthine 
were incubated with cell-free rumen filtrate ( 88 -I I $\%$ was recovered). Adenine and guanine were removed to a small extent but $80 \%$ of both survived after $4 \mathrm{~h}$ incubation. Part of the adenine lost (about $13 \%$ of the initial concentration) was recovered as hypoxanthine, but the products replacing the lost guanine were not detected.

After incubation of adenosine, guanosine, thymidine, uridine, cytidine, inosine, and xanthosine with cell-free filtrate, 90-105\% of all except cytidine were recovered after $4 \mathrm{~h}$. Of the cytidine, $23 \%$ of the initial concentration was recovered as cytosine and $80 \%$ was unchanged.

Nucleotides $\left(2^{\prime}, 3^{\prime}\right.$ mixed isomers) on incubation for $4 \mathrm{~h}$ with cell-free filtrate were also only slightly degraded, and recoveries of original substrates were $80,94,84$, and $92 \%$ for adenylic, uridylic, guanylic, and cytidylic acids respectively. Approximately $15 \%$ of the guanylic acid and $10 \%$ of the adenylic acid were recovered as the corresponding nucleosides.

\section{DISCUSSION}

Experiments in which RNA and DNA were incubated for up to $4 \mathrm{~h}$ with rumen contents in vitro (McAllan \& Smith, 1973) showed a transient formation of nucleotides and nucleosides (some of which persisted even after $4 \mathrm{~h}$ when DNA was used) but considerable eventual accumulation of purine and pyrimidine bases. Bases containing side amino groups were not recovered but were partly replaced by their oxy analogues. From the relative amounts of the bases recovered it appeared that xanthine, uracil, thymine, and hypoxanthine were the most resistant to degradation; and guanine, cytosine, and adenine the least resistant. There was little evidence to show the pathways by which the end-products formed. The present results suggest that when nucleotides and nucleosides are incubated with rumen fluid, the products formed are nearly identical. It seems probable therefore that, after depolymerization, the first step in the degradation of RNA and DNA is a simple dephosphorylation of the nucleotides to the corresponding nucleosides. Results obtained when nucleosides were incubated with rumen fluid (sce Figs 3, 4 and 5) suggest that several main pathways are followed.

Adenosine is rapidly deaminated (see Fig. $4(a)$ ) but the base adenine is fairly resistant to degradation (see Fig. I) and it appears that the principal pathway of breakdown of adenosine is deamination followed by glycosidic cleavage. Guanosine is also rapidly removed from the incubation mixture (see Fig. 3), whereas its desamino counterpart, xanthosine, is not (see Fig. 3), but no xanthosine was found in incubates of rumen fluid with guanosine. The base guanine, on the other hand, is also rapidly removed (see Fig. 1) and from this it would seem that guanosine is degraded first by glycosidic cleavage and then by deamination. Similar findings were reported (Colla, Craveri \& Craveri, 1965) for guanosine breakdown by non-rumen bacteria. Deamination of cytidine derivatives occurs at all levels but the most resistant appears to be cytidine itself (see Fig. 3), suggesting that deamination during nucleic acid breakdown may occur at the nucleotide level. Uridine and thymidine follow similar pathways, both being rapidly degraded to the corresponding base (see Fig. 5).

The relative resistances of the final oxy bases to further degradation are in general agreement with the previous findings with RNA and DNA (McAllan \& Smith, I973). 


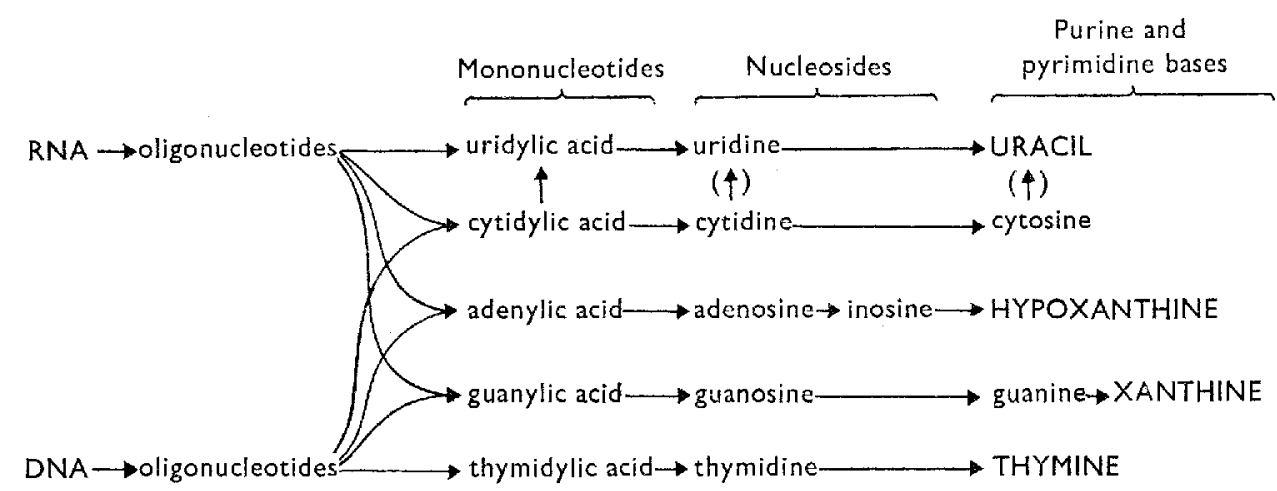

Fig. 6. Probable main pathways of nucleic acid degradation by rumen bacteria. The nucleotides derived from RNA are ribonucleotides and those from DNA are deoxyribonucleotides.

Even when, for example, xanthine was added direct to fresh rumen fluid 0.63 was recovered in $4 \mathrm{~h}$. This suggests that the reason for the differences observed between in vivo and in vitro survival of the oxy bases (McAllan \& Smith, 1973) is that they are absorbed across the rumen wall, metabolized in it, or both, although it is possible that the metabolic rates of the bacteria are more efficient in vivo than in vitro. Rumen protozoa utilize preformed purine and pyrimidine bases (Kidder, I967), but the particular animals used in this and earlier studies (McAllan \& Smith, 1973) were almost certainly protozoa-free (Smith \& McAllan, I973). Ruminants on high-roughage or pasture diets may ingest appreciable quantities of free purines (Ferguson $\&$ Terry, 1953) and nucleic acids (Smith \& McAllan, 1970) and it is possible that appreciable amounts of purine or pyrimidine bases are absorbed. The proposed main pathways of nucleic acid degradation by rumen bacteria are shown in Fig. 6 .

No information is available from the present work on the possible fate of bases which were degraded in vitro. Horst (1965) and Doetsch \& Jurtshuk (1957) have shown pyrimidine and purine base catabolism respectively during incubations of these derivatives with rumen bacterial suspensions in vitro.

The present studies were carried out with materials from the rumens of calves on one particular diet, but it has been shown (McAllan \& Smith, I973) that the degradations of nucleic acids, in vitro, using materials from the rumens of calves, sheep, and cows on similar diets, and from calves on a variety of diets, were very similar. The degradation pathways in the present work have been studied using RNA derivatives (with the exception of thymine compounds) but DNA is degraded similarly to RNA during in vitro incubation with rumen fluid (McAllan \& Smith, 1973) and the catabolism of deoxyribonucleosides and ribonucleosides by bacteria (Hammer-Jespersen, Munch-Petersen, Nygaard \& Schwartz, 1971) yield the same ultimate purine endproducts.

We thank Mrs S. J. Askew for supervising the conduct of the animal experiments and Dr H. L. Buttle and Mr S. C. Watson for carrying out all surgical operations. 


\section{REFERENCES}

Beck, C. F., Ingraham, J. L., Neuhard, J. \& Thomassen, E. (1972). F. Bact. 110, 219.

Colla, C., Craveri, R. \& Craveri, A. (1965). Annali Microbiol. r5, 75.

Doetsch, R. N. \& Jurtshuk, P. (1957). Misc. Publs agric. Exp. Stn Univ. Md no. 129, p. 8.

Ferguson, W. S. \& Terry, R. A. (1953). Nature, Lond. 172, 346.

Gregory, M. E. (1954). Br. \%. Nutr. 8, 340.

Hammer-Jespersen, K., Munch-Petersen, A., Nygaard, P. \& Schwartz, M. (I97 I). Eur. Y. Biochem. I9, 533 .

Hayaishi, O. \& Kornberg, A. (r952). 7. biol. Chem. r97, 7r7.

Horst, C. J. G. van der (1965). Tijdschr. Diergeneesk. 90, 361.

Kidder, G. W. (r967). In Chemical Zoology, vol. I, Protozoa, p. 93 [G. W. Kidder, editor]. New York: Academic Press.

Lichtenstein, J., Barner, H. D. \& Cohen, S. S. (rg60).7. biol. Chem. 235, 457.

McAllan, A. B. \& Smith, R. H. (1973). Br. Y. Nutr. 29, 33 I.

Smith, R. H. \& McAllan, A. B. (1970). Br. J. Nutr. 24, 545. 